\title{
An electrochemical sensor based on a graphene/AuNP nanocomposite for the determination of prolyl hydroxylase
}

\author{
Lintao Jiang, Qinghao Guo, Shijiang Yang and Jun Cai ${ }^{*}$ \\ Department of Emergency and Trauma Surgery, The Central Hospital of Wuhan, Tongji Medical \\ College, Huazhong University of Science and Technology. Wuhan, Hubei, 430014, P.R. China \\ *E-mail: caijunclcj@ sina.com
}

doi: $10.20964 / 2018.05 .17$

Received: 24 November 2017 / Accepted: 16 January 2018 / Published: 10 April 2018

\begin{abstract}
Prolyl hydroxylase (PHD1) is a vital indicator of a patient's health level evaluation after liver metastases. The present study reports the fabrication of a state-of-the-art and highly conductive graphene-gold nanoparticle-modified glassy carbon electrode (GCE-graphene-AuNPs) for application in PHD1 analysis. Fabrication of the composite was achieved by the successive electrodeposition of $\mathrm{Au}$ NPs and graphene onto the GCE surface. It was found that the oxidization was a diffusioncontrolled, irreversible process over a $\mathrm{pH}$ range of 3.0 to 10. Over a paclitaxel concentration range of 0.01 to $2 \mathrm{mM}$, a linear relationship was found between the concentration and the anodic peak current. Additionally, the limit of detection (LOD) was calculated as $0.004 \mathrm{mM}$.
\end{abstract}

Keywords: Electrochemical determination; Prolyl hydroxylase; Graphene; Au nanoparticle; Liver injury

\section{FULL TEXT}

(C) 2018 The Authors. Published by ESG (www.electrochemsci.org). This article is an open access article distributed under the terms and conditions of the Creative Commons Attribution license (http://creativecommons.org/licenses/by/4.0/). 